\title{
Nowe technologie i niepełnosprawność
}

Grzegorz Całek

(D) https://orcid.org/0000-0002-0952-4826

Uniwersytet Warszawski

Jakub Niedbalski

(D) https://orcid.org/0000-0002-2803-7628

Uniwersytet Łódzki

Mariola Racław

https://orcid.org/0000-0002-7614-0507

Uniwersytet Warszawski

Dorota Żuchowska-Skiba

(D) https://orcid.org/0000-0002-8198-9900

AGH, Akademia Górniczo-Hutnicza w Krakowie 


\title{
Streszczenie
}

Artykuł jest wstępem do monografii poświęconej ukazniu złożonych relacji między nowymi technologiami a niepełnosprawnością. Z jednej strony są one postrzegane jako narzędzia włączenia i emancypacji, a z drugiej stanowią źródło wykluczenia osób z niepełnosprawnościami. Naszym celem jest ukazanie kontekstowych zależności pomiędzy rozwiązaniami technologicznymi a funkcjonowaniem osób $\mathrm{z}$ niepełnosprawnościami w życiu codziennym. Temat ten dziś jest niezwykle ważny, bowiem w związku z epidemią COVID-19 rola i znaczenie nowoczesnych technologii wzrosła. Wynikało to z konieczności przeniesienia wielu codziennych aktywności do przestrzeni wirtualnej. Zmiany te miały istotne konsekwencje dla osób z niepełnosprawnościami, gdyż zostały one dotknięte ograniczeniami w poruszaniu się, dostępie do opieki medycznej oraz edukacji i możliwości korzystania z przysługujących im praw do wsparcia w samodzielnym i niezależnym życiu. Osoby te w ciągu bardzo krótkiego czasu musiały przenieść swoje aktywności do przestrzeni wirtualnej.

\section{Słowa kluczowe}

biotechnologie, cyfrowe wykluczenie, niepełnosprawność, nowe technologie, reprezentacje niepełnosprawności.

\section{New technologies and disability}

\begin{abstract}
The article is an introduction to a monograph devoted to showing the complex relations between new technologies and disability. On the one hand, they are seen as a tool for inclusion and emancipation, and on the other hand, they are a source of exclusion for people with disabilities. Our goal is to show the contextual relationships between technological solutions and the functioning of people with disabilities in everyday life. This topic is extremely important today because in connection with the COVID-19 epidemic, the role and importance of modern technologies has increased. This was due to the necessity to transfer many daily activities to virtual space. These changes had significant consequences for people with disabilities who were affected by limitations in movement, access to medical care and education and the possibility of exercising their rights to support in independent and independent life, and had to transfer their activities to a virtual space within a very short time.
\end{abstract}

\section{Keywords}

biotechnologies, disability, digital divide, new technologies, representations of disability. 
$\mathrm{R}$ elacje między nowymi technologiami a niepełnosprawnością cechuje złożoność wynikająca z kontekstowych zależności pomiędzy rozwiązaniami technologicznymi a ich beneficjentami, którymi są osoby z niepełnosprawnościami (Sheldon, 2003). W literaturze przedmiotu można odnaleźć cztery kluczowe perspektywy opisujące zależności pomiędzy technologicznymi rozwiązaniami a korzystającymi z nich osobami z niepełnosprawnościami.

Pierwsze ujęcie koncentruje się na koncepcji cyfrowego wykluczenia osób z niepełnosprawnościami (zob. Ellis, Kent, 2011). Stanowi ono konsekwencję wzrostu znaczenia nowoczesnych technologii w różnych sferach życia jednostek we współczesnych społeczeństwach (Castells, 2011). W wyniku tego procesu dostęp do technologii i umiejętności posługiwania się nimi stały się niezwykle istotnymi kompetencjami, które miały istotne znaczenie w aktywnościach o charakterze ekonomicznym, edukacyjnym, społecznym, psychologicznym i kulturowym. Prowadzone badania wskazują, że aktywne korzystanie z technologii informatyczno-komunikacyjnych i sieciowych wpływa na wysokość dochodów (DiMaggio, Bonikowski, 2008), zdrowie psychiczne jednostek, umożliwia redukcję ich poczucie osamotnienia i izolacji (Cotten, Ford, Ford, Hale, 2014; Cotten, Anderson, McCullough, 2013) oraz zwiększa poziom kapitału społecznego (Chen, 2013). Jednocześnie brak dostępu do nowoczesnych technologii lub niedostateczne umiejętności korzystania z nich mają wpływ na relacje społeczne, aktywność zawodowową i ogólną jakość życia (DiMaggio, Hargittai, Celeste, Shafer, 2004). Poziom kompetencji i wzory korzystania z technologii informatycznych wpływają też na pozycje jednostek w strukturze społecznej (Blank, Groselj, 2014) oraz ich status społeczny (Zillion, Hargittai, 2009). $\mathrm{W}$ tym sensie dostępność oraz umiejętności korzystania z technologii sieciowych stanowią czynniki generujące nowy typ rozwarstwienia społecznego (DiMaggio, Hargittai, 2001; Zdrodowska, 2018, s. 16). Z tego względu nierówności w dostępie i korzystaniu $\mathrm{z}$ internetu mogą mieć istotne konsekwencje prowadzące do społecznego a także ekonomicznego wykluczenia tych kategorii osób w sytuacji, gdy mają mniejsze możliwości oraz kompetencje w zakresie korzystania z nowoczesnych technologii w porównaniu do reszty społeczeństwa (Van Dijk, 2005; Witte, Mannon, 2010).

Perspektywa ta wyrasta $\mathrm{z}$ koncepcji determinizmu technicznego, która zakładała, że charakter technologii i kierunek zmiany są z góry określone i podlegają „logice technicznej” lub stanowią efekt „imperatywu ekonomicznego”. Zatem w takim ujęciu zmiany technologiczne generują zmiany społeczne i organizacyjne, które są niejako narzucone społeczeństwu (Yoshinaka, Clausen, Hansen, 2003). W rezultacie powoduje to wykluczenie całych kategorii społecznych ze względu na płeć, wiek, status społeczno-ekonomiczny, rasę/etniczność, poziom wykształcenia, miejsce zamieszkania, status zawodowy oraz sytuację rodzinną. Ma to bezpośredni wpływ na odmienne wykorzystywanie zasobów oraz funkcjonalności sieci, przyczyniając się do powstania nierówności. Czynnikiem wykluczającym jest również niepełnosprawność (por. Vicente, López, 2010; Dobransky, Hargittaib, 2016; Żuchowska-Skiba, 2020; Norris, 2001; Warschauer, 2013).

Drugie podejście skupia się na włączającym charakterze technologii. W tym podejściu dokonująca się pod wpływem nowych technologii transformacja społeczeństwa sprzyjała włączaniu osób z niepełnosprawnościami w różne sfery życia społecznego (Finkelstein, 
1980, s. 8-9). Zmiany dokonujące się w postindustrialnej gospodarce spowodowały, że źródłem wzrostu i zysku stała się wiedza, a jednocześnie docenione zostały umiejętności związane z wytwarzaniem i przetwarzaniem informacji (Castells, 2011, s. 205-206). Pozwoliło to na zniesienie istniejącego $\mathrm{w}$ dobie industrializmu powiązania pomiędzy sprawnością fizyczną i tempem wykonywania pracy a produktywnością. Możliwa stała się zmiana pozycji osób niepełnosprawnych na rynku pracy, ponieważ ich niepełnosprawność fizyczna nie stanowiła już podstawy wykluczenia. Zmiany te umożliwiały bardziej samodzielne życie osobom z niepełnosprawnościami przez otwarcie rynku pracy, co pozwoliło im odzyskać niezależność i włączyć się do głównego nurtu życia społecznego (Finkelstein, 1980, s. 11).

Trzecia perspektywa - biotechnologiczna zakłada, że uszkodzenia i upośledzenia mogą zostać wyeliminowane dzięki rozwiązaniom technologicznym. Ujęcie to jest rozwijane przez ekspertów z dziedziny medycyny i nowych technologii, których celem jest opracowanie odpowiednich narzędzi, pozwalających usunąć ograniczenia o biologicznym charakterze tkwiące w jednostkach, aby zwiększyć poziom ich niezależności (Stienstra, Troschuk, 2005). Podejściu temu towarzyszy przekonanie, że nowe rozwiązania techniczne skorygują osobiste braki poszczególnych osoby (Roulstone, 1998, s. 11). Tak rozumiane technologie określane są jako technologie asystujące, bowiem wspomagają one jak najbardziej samodzielne funkcjonowanie osób z niepełnosprawnościami w życiu codziennym (Smith, 1998, s. 115; De Witt, 1991, s. 317). Pojęcie to jest bardzo szerokie i obejmuje zarówno implanty ślimakowe, aparaty słuchowe, protezy, białe laski, wózki dla osób z trudnościami w poruszaniu się, a także rozwiązania, które nie były dedykowane osobom z niepełnosprawnościami, ale są przez nie wykorzystywane ze względu na ich użyteczność w realizacji określonych zadań lub codziennych aktywności (por. Zdrodowska, 2018, s. 14). Taki charakter ma powszechne wykorzystywanie przez osoby $z$ niepełnosprawnościami narzędzi oferowanych przez programy komputerowe oraz używanie portali społecznościowych, a także innych funkcjonalności i narzędzi dostępnych w internecie (Fiszer, 2016). Jednak pomimo potencjału włączającego, tkwiącego w nowoczesnych technologiach, wiele tak zwanych technologii asystujących opiera się na skomplikowanych rozwiązaniach, które - zamiast wspomagać - mogą generować kłopoty $z$ obsługą lub utrzymaniem sprawności technicznej, w efekcie prowadząc do wtórnego wykluczenia (Zdrodowska, 2018, s. 16).

Czwarte ujęcie relacji pomiędzy technologiami i niepełnosprawnościom skupia się na ich emancypacyjnym potencjale w wymiarze społecznym, politycznym oraz kulturowym (Sheldon, 2003). W takiej pespektywie internet odgrywa istotną rolę w promowaniu partycypacji społecznej oraz politycznej, przyczyniając się do budowania poczucia wspólnoty osobom z niepełnosprawnościami, oferując im możliwość zaangażowania się w społeczności skupiające jednostki o podobnych problemach i doświadczeniach (Wright, Bell, 2003). W efekcie przyczyniało się to do wzmacniania znaczenia wirtualnych społeczności osób z niepełnosprawnościami (Polat, 2005; Żuchowska-Skiba, 2017). Prowadzone badania pokazują między innymi korzyści płynące z internetowych społeczności (Obst, Stafurik, 2010). Uczestnictwo w nich pozwala na znalezienie wsparcia oraz daje możliwość utrzymywania kontaktów interpersonalnych i budowania wzajemnych 
relacji (Kampert, Goreczny, 2007; Morris, 2001). Ważną rolę odgrywają też portale społecznościowe jako przestrzeń dla debaty o sytuacji osób z niepełnosprawnościami, a także jako narzędzie walki o ich prawa oraz aktywizmu w sferze online (Johnson, Moxon, 1998, s. 255; Sheldon, 2010, s. 155; Pearson, Trevisan, 2015). Technologie reprezentacji będą w takim ujęciu skupiały się nie tylko na odtworzeniu sposobów prezentowania niepełnosprawności, ale również na aktywnościach samych osób z niepełnosprawnościami, służących kreowaniu własnych przekonań o niepełnosprawności. W tym sensie stanowią one swoisą tubę dla osób z niepełnosprawnościami w drodze ku ich emancypacji (Zdrodowska, Kłos, 2018, s. 10). W takim podejściu internet i nowe technologie odgrywają istotną rolę, dają bowiem szersze niż wcześniej możliwości rozpowszechniania własnych przedstawień niepełnosprawności na blogach lub profilach oraz w mediach społecznościowych (por. Thoreau, 2006; Goggin, Noonan, 2007).

Zarysowane perspektywy pokazują, że w nowoczesnych technologiach jednocześnie drzemie możliwość bycia narzędziem włączenia i emancypacji, ale również źródło wykluczenia osób z niepełnosprawnościami (Davis, Hirschl, Stack, 1997, s. 6). Za sprawą epidemii wywołanej wirusem COVID-19 przyspieszeniu uległ proces wirtualizacji życia codziennego. W wyniku konieczności przeniesienia znacznej części aktywności do internetu wzrosła rola tego medium jako przestrzeni, w ramach której realizowane były zarówno praca, edukacja, uczestnictwo w kulturze, opieka medyczna, jak i działania związane z codziennym życiem. Miało to daleko idące konsekwencje dla osób z niepełnosprawnościami, które zostały dotknięte ograniczeniami w poruszaniu się, dostępie do opieki medycznej oraz edukacji i możliwości korzystania z przysługujących im praw do wsparcia w samodzielnym i niezależnym życiu (por. Smith, MacLachlan, Ebuenyi, Holloway, Austin, 2021; Armitage, Nellums, 2020). Dzięki nowym mediom, portalom społecznościowym oraz poczcie elektronicznej osoby z niepełnosprawnościami mogły, pomimo utrzymywania zalecanej izolacji, podejmować aktywności zorientowane na walkę o swoje prawa, nagłaśniać praktyki dyskryminacyjne i wykluczające oraz budować przestrzeń pozwalającą na uzyskanie informacji, pomocy i wsparcia osobom, które go potrzebują w okresie epidemii (por. Hill, 2020).

Złożone relacje między technologią a niepełnosprawnością zostały przedstawione w poszczególnych rozdziałach składających się na ninieszą monografię. Ze względu na różne perspektywy ukazujące wpływ technologii na codzienne aktywności oraz działania podejmowane przez osoby $\mathrm{z}$ niepełnosprawnościami monografia podzielona została na trzy części.

Pierwsza zatytułowana „Nowe technologie” skupia się na ukazaniu relacji pomiędzy technologiami internetowo-medialnymi a niepełnosprawnością. Rozpoczyna ją rozdział „Nowe narzędzia i technologie komunikacyjne dla osób niepełnosprawnych fizycznie, intelektualnie i społecznie oraz seniorów”. Tomasz Sahaj prezentuje w nim istniejące w Polsce rozwiązania technologiczne umożliwiające zdalną komunikację oraz nadzór i opiekę nad osobami, które jej potrzebują. Przedstawia narzędzia tworzone zarówno przez pojedynczych aktorów społecznych, jak i instytucje komercyjne, organizacje społeczne czy podmioty rządowe. Technologie te wspierają osoby społecznie marginalizowane i niepełnosprawne, w szczególności z deficytami mowy, słuchu i wzroku, ułatwiając 
im komunikację oraz integrację społeczną. Autor opisując istniejące narzędzia wskazuje, że w dobie pandemii COVID-19, która w 2020 roku dwukrotnie spowodowała izolację społeczną, przestały one być uzupełnieniem wsparcia osób z niepoprawnościami a stały się głównym kanałem udzielanej pomocy.

W kolejnym rozdziale pod tytułem „Telemedycyna a niepełnosprawność wzrokowa - szanse, zagrożenia, wyzwania" Katarzyna Binder-Olibrowska porusza bardzo istotną kwestię związaną z dostępnością i funkcjonalnością telemedycyny dla osób z niepełnosprawnością wzroku, a także wskazuje na nierówności w dostępie do opieki zdrowotnej doświadczanej przez tę kategorię osób. Autorka analizuje telemedycynę, odpowiadając na pytanie, czy taki sposób realizacji usług, stanowi zagrożenie dla osób z niepełnosprawnością wzroku, czy też szansę na równy dostęp do świadczeń medycznych.

W rozdziale zatytułowanym „Internet w służbie rodziców dzieci z niepełnosprawnością intelektualną" Jakub Niedbalski przedstawia wyniki badań jakościowych opartych na procedurach metodologii teorii ugruntowanej i ukazuje znaczenie oraz funkcje internetu, jakie przypisują mu rodzice osób z niepełnosprawnościami intelektualnymi.

Rozdział kończący pierwszą część monografii zatytułowany „Edukacja zdalna. Adaptacja procesu dydaktycznego do potrzeb osób z niepełnosprawnościami” ma charakter poradnikowo-praktyczny. Justyna Migacz ukazuje w nim ze swojej perspektywy użytkownika, ograniczenia i możliwości adaptacji kształcenia online, tak aby było ono bardziej dostępne i przyjazne dla osób z niepełnosprawnościami.

Cześć druga książki, nosząca tytuł „Przestrzenie wirtualizacji”, ma na celu ukazanie obszarów życia codziennego oraz sposobów postrzegania samych siebie przez osoby z niepełnosprawnościami, które ulagają zmianom pod wpływem nowych technologii.

Rozpoczyna ją rozdział pod tytułem „Konstruowanie tożsamości w Internecie - młodzi ludzie z niepełnosprawnością intelektualną" Rafała Maciąga, który porusza ważną dziś kwestię kształtowania tożsamości przez osoby z niepełnosprawnością intelektualną, będących użytkownikami internetu. Z jednej strony społecznościowy charakter sieci umożliwia nawiązywanie kontaktów i budowanie relacji online, z drugiej strony naraża na hejt i agresję, przez co wywiera wpływ na budowane projekty tożsamościowe oraz przyjmowany przez nie kształt.

W kolejnym rozdziale zatytułowanym „Wirtualizacja działań społecznych i obywatelskich - szanse i zagrożenia - na przykładzie Kongresu osób z niepełnosprawnościami” Zbigniew Głąb pokazuje wyzwania, jakie postawiła konieczność wirtualizacji Kongresu przed osobami z niepełnosprawnościami w czasie epidemii. Autor koncetruje się w nim na ukazaniu obaw, zagrożeń, ale także zalet zmiany sposobu organizacji Kongresu, jakie towarzyszyły uczestnikom tego wydarzenia zrealizowanego online.

Monika Dubiel w rozdziale zatytułowanym „Kultura zdalna: szansa na uczestnictwo czy zagrożenie izolacją? Przypadek osób z niepełnosprawnością wzroku" ukazuje fenomen uczestnictwa online w kulturze w perspektywie jej dostępności dla osób z niepełnosprawnością wzroku. Autorka podejmuje ważną kwestie związaną z dostępnością treści kultury upowszechnianych za pomocą technologii, umożliwiających uczestnictwo online.

Z kolei w rozdziale „Dostępność Zintegrowanej Platformy Edukacyjnej dla uczniów ze specjalnymi potrzebami edukacyjnymi" Joanna Wojtyńska prezentuje oraz analizuje 
pod kątem dostępności i funkcjonalności dla dzieci ze specjalnymi potrzebami edukacyjnymi platformę, która w okresie edukacji online i hybrydowej była oferowana jako wsparcie dla nauczycieli i uczniów.

W trzeciej części monografii zatytułowanej „Doświadczenia z czasu pandemii” ukazane są sposoby wykorzystania technologii informatycznych w kształceniu, rehabilitacji oraz rekreacji osób z niepełnosprawnościami w okresie epidemii, która spowodowała konieczność pozostania w domu i ograniczenia fizycznych kontaktów. Tę część rozpoczyna artykuł Joanny Wojtyńskiej „Dostępność Zintegrowanej Platformy Edukacyjnej dla uczniów ze specjalnymi potrzebami edukacyjnymi” prezentujący dostowania tej platformy do wymagań uczniów ze specjalnymi potrzebami edukacyjnymi.

Anna Gutowska i Joanna Sztobryn-Giercuszkiewicz w rozdziale „Diagnoza kształcenia zdalnego wśród studentów i doktorantów z niepełnosprawnościami w sytuacji pandemii COVID-19 - wybrane zagadnienia raportu z badań" przestawiają ilościowe wyniki badań prowadzonych wśród studentów z niepełnosprawnościami w okresie epidemii na temat edukacji zdalnej.

W kolejnym rozdziale zatytułowanym „Muzykoterapia online w czasie pandemii” Edyta Górska przedstawia sposoby realizowania terapii online dla osób z niepełnosprawnościami. Autorka skupia się w nim na ukazaniu możliwości, ale także ograniczeń tej formy działań terapeutycznych. Wskazuje również na jej zalety i wady zarówno dla uczestników, jak i osób prowadzących muzykoterapię.

Kamila Albin, autorka rozdziału pod tytułem „Joga w czasach zarazy - możliwości i wyzwania praktykowania jogi online przez osoby z dysfunkcją wzroku", stosując metodę autoetnografii ukazuje $\mathrm{z}$ własnej perspektywy doświadczenia związane $\mathrm{z}$ realizacją online działań o charakterze rekreacyjno-sportowych, jakim jest ćwiczenie jogi.

Monografię zamyka rozdział Aleksandry Różyckiej zatytułowany „Poradnictwo prawne i obywatelskie świadczone na odległość dla osób z niepełnosprawnością. Obserwacje $\mathrm{z}$ okresu pandemii”. Autorka opisuje oraz poddaje analizie kwestie związane z udzielaniem świadczeń z zakresu poradnictwa prawnego i obywatelskiego, które podobnie jak inne aktywności musiało być realizowane za pośrednictwem technologii internetowych w trybie online.

Oddając do rąk czytelników kolejną z serii monografii, które zostały wydane pod auspicjami Sekcji Socjologii Niepełnosprawności, chcieliśmy przede wszystkim pokazać, jak w różnych kontekstach oraz w odniesieniu do zróżnicowanych perspektyw kształtują się relacje technologiią i niepełnosprawności. Tym samym mamy nadzieję, że niniejsza książka przyczyni się to do lepszego zrozumienia na gruncie studiów o niepełnosprawności złożoności oraz zależności istniejących pomiędzy rozwiązaniami technologicznymi a ich obecnością w życiu osób z niepełnosprawnościami. 


\section{BIBLIOGRAFIA}

Armitage, R., Nellums, L.B. (2020). The COVID-19 Response Must Be Disability Inclusive. The Lancet. Public Health, 5(5), 257-259. https://doi.org/10.1016/S2468-2667(20)30076-1, https://www.thelancet.com/pdfs/journals/lanpub/PIIS2468-2667(20)30076-1.pdf

Blank, G., Groselj, D. (2014). Dimensions of Internet use: amount, variety, and types. Information. Communication and Society, 17(4), 417-435. https://doi.org/ 10.1080/1369118X.2014.889189

Castells, M. (2011). Społeczeństwo sieci. Wydawnictwo Naukowe PWN.

Chen, W. (2013). The Implications of Social Capital for the Digital Divides in America. The Information Society, 29(1), 13-25. https://doi.org/10.1080/01972243.2012.739265

Cotten, S.R., Anderson, W.A., McCullough, B.M. (2013). Impact of internet use on loneliness and contact with others among older adults: cross-sectional analysis. Journal of medical Internet research, 15(2), 39-42. https://doi.org/ 10.2196/jmir.2306

Cotten, S.R., Ford, G., Ford, S., Hale, T.M. (2014). Internet use and depression among retired older adults in the united states: a longitudinal analysis. Journals of Gerontology, Series B: Psychological Sciences and Social Sciences, 69(5), 763-771. https://doi.org/10.1093/ geronb/gbu018

Davis, J., Hirschl, T., Stack, M. (1997). Introduction: Integrated circuits, circuits of capital, and revolutionary change. W: J. Davis, T. Hirschl, M. Stack (red.), Cutting Edge: Technology, Information, Capitalism and Social Revolution (s. 1-10). Verso.

De Witt, J.C. (1991). The role of technology in removing barriers. The Milbank Quarterly, 69 (sup. 1-2), 313-332. PMID: 1837838

DiMaggio, P., Bonikowski, B. (2008). Make Money Surfing the Web? The Impact of Internet Use on the Earnings of U.S. Workers. American Sociological Review, 73, 227-250. https:// doi.org/10.1177/000312240807300203

DiMaggio, P., Hargittai, E. (2001). From the 'Digital Divide' to 'Digital Inequality': studying Internet use as penetration increases. Working paper series 15. Princeton University Center for Arts and Cultural Policy Studies. https:/culturalpolicy.princeton.edu/sites/ culturalpolicy/files/wp15_dimaggio_hargittai.pdf

DiMaggio, P., Hargittai, E., Celeste, C., Shafer, S. (2004). Digital Inequality: From Unequal Access to Differentiated Use. W: K. Neckerman (red.), Social Inequality (s. 355-400). Russell Sage Foundation.

Dobransky, K., Hargittaib, E. (2016). Unrealized Potential: Exploring the Digital Disability Divide. Poetics, 58, 18-28. https://doi.org/10.1016/j.poetic.2016.08.003

Elis, K., Mike, K. (2011). Disability and New Media. Routledge.

Finkelstein, V. (1980). Attitudes and disabled People. Lamport Gilbert Printers Ltd. https:// disability-studies.leeds.ac.uk/wp-content/uploads/sites/40/library/finkelstein-attitudes. pdf

Goggin, G., Noonan, T. (2007). Blogging Disability: The Interfacebetween New Cultural Movements and Internet Technology. W: A. Bruns, J. Jacobs (red.), Uses of Blogs (s. 161172). Peter Lang. 
Hill, C. (2020). The cripples will save you': a critical coronavirus message from a disability activist. https://creakyjoints.org/living-with-arthritis/coronavirus-disability-activism

Johnson, L., Moxon, E. (1998). In Whose Service? Technology, Care and Disabled People: The Case For A Disability Politics Perspective. Disability and Society, 13(2), 241-258. https://doi.org/10.1080/09687599826812

Kampert, A.L., Goreczny, A.J. (2007). Community involvement and socialization among individuals with mental retardation. Research in Developmental Disabilities, 28(3), 278-286. https://doi.org/10.1016/j.ridd.2005.09.004

Masłyk, T., Migaczewska, E. (2014). Charakter użytkowania internetu przez osoby niepełnosprawne i sprawne w perspektywie cyfrowego wykluczenia - analiza porównawcza. Studia Socjologiczne, 2(213), 175-201.

Morris, J. (1991). Pride Against Prejudice: Transforming Attitudes to Disability. Womens Press. http://repositoriocdpd.net:8080/handle/123456789/605.

Norris, P. (2001). The Digital Divide: Civic Engagement, Information Poverty and the Internet Worldwide. Cambridge University Press. https://doi.org/10.1017/CBO9781139164887

Obst, P., Stafurik, J. (2010). Online we are all able bodied: Online psychological sense of community and social support found through membership of disability-specific websites promotes well-being for people living with a physical disability. Journal of Community \& Applied Social Psychology, 20(6), 525-531. https://doi.org/10.1002/casp.1067

Pearson, C., Trevisan, F. (2015). Disability activism in the new media ecology: campaigning strategies in the digital era. Disability \& Society, 30(6), 924-940. https://doi.org/10.1080/0 9687599.2015.1051516

Polat, R.K. (2005). The Internet and Political Participation: Exploring the Explanatory Links. European Journal of Communication, 20(4), 435-459. https://doi. org/10.1177/0267323105058251

Roulstone, A. (1998). Enabling Technology: Disabled People, Work and New Technology. Open University Press.

Sheldon, A. (2003). Changing Technology. W: J. Swain, S. French, C. Barnes, C. Thomas (red.), Disabling Barriers - Enabling Environments (s. 155-160). Sage.

Smith, D.C. (1998). Assitive technology. Funding options and strategies. Mental and Physical Disability Law Reporter, 1(22), 115-123. PMID: 9520508

Smith, E., MacLachlan, M., Ebuenyi, I., Holloway, C., Austin, V. (2021). Developing inclusive and resilient systems: COVID-19 and assistive technology. Disability and Society, 36(1), 151-154. https://doi.org/10.1080/09687599.2020.1829558

Srinuan, C., Bohlin, E. (2011). Understanding the digital divide: A literature survey and ways forward, 22nd European Regional Conference of the International Telecommunications Society (ITS): „Innovative ICT Applications - Emerging Regulatory, Economic and Policy Issues", Budapest, Hungary, 18th-21st September, 2011. International Telecommunications Society (ITS), Calgary. https://www.econstor.eu/bitstream/10419/52191/1/672623358.pdf

Stienstra, D., Troschuk, L. (2005). Engaging Citizens with Disabilities in Democracy. http:// dsq-sds. org/article/view/550/727 
Thoreau, E. (2006). Ouch!: An Examination of the Self-representation of Disabled People on the Internet. Journal of Computer-MediatedCommunication, 11(2), 442-468. https://doi. org/10.1111/j.1083-6101.2006.00021.x

Van Dijk, J. (2005). The Deepening Divide: Inequality in the Information Society. SAGE. https://us.sagepub.com/en-us/nam/the-deepening-divide/book226556

Vicente, M.R., López, A.J. (2010). A multidimensional analysis of the disability digital divide: Some evidence for Internet use. The Information Society, 26, 48-64. https://doi. org/10.1080/01615440903423245

Warschauer, M. (2013). Technology and Social Inclusion: Rethinking the Digital Divide. MIT Press.

Witte, J.C., Mannon, S.E. (2010). The Internet and Social Inequalities. Routledge.

Wright, K.B., Bell, S.B., Wright, K.B., Bell, S.B. (2003). Health-Related Support Groups on the Internet: Linking Empirical Findings to Social Support and Computer-Mediated Communication Theory. Journal of Health Psychology, 8(1), 39-54. https://doi. org/10.1177/1359105303008001429

Yoshinaka, Y., Clausen, C., Hansen, A. (2003). The Social Shaping of Technology: A New Space for Politics?. W: A. Grunwald (red.), Technikgestaltung zwischen Wunsch und Wirklichkeit (s. 117-137). Springer, Berlin, Heidelberg. https://doi.org/10.1007/978-3-64255473-5_7

Zdrodowska, M. (2018). Technologia jako narzędzie społecznej dystynkcji. Nieoczywiste relacje techniki i niepełnosprawności. Kultura Współczesna, 3(102), 13-26. https://doi. org 10.26112/kw.2018.102.02

Zdrodowska, M., Kołos, S. (2018). Niepełnosprawność - techniki wsparcia, techniki reprezentacji. Kultura Współczesna, 3(102), 10-12. https://doi.org/10.26112/kw.2018.102.01

Zillion, N., Hargittai, E. (2009). Digital distinction: status specific Internet uses. Social Science Quarterly, 90(2), 274-291. https://doi.org/10.1111/j.1540-6237.2009.00617.x

Żuchowska-Skiba, D. (2017). W kierunku integracji - znaczenie serwisów społecznościowych dla osób niepełnosprawnych w Polsce. W: J. Niedbalski, M. Racław, D. Żuchowska-Skiba (red.), Oblicza niepełnosprawności w teorii i praktyce (s. 281-306). Wydawnictwo Uniwersytetu Łódzkiego.

Żuchowska-Skiba, D. (2020). Wykluczenie cyfrowe osób z niepełnosprawnościami - perspektywy badawcze. W: G. Całek, J. Niedbalski, D. Żuchowska-Skiba (red.), Jak badać zjawisko niepetnosprawności. Szanse i zagrożenia założeń teoretycznych i metodologicznych studiów nad niepełnosprawnością (s. 195-211). Wydawnictwo Uniwersytetu Łódzkiego. 